\title{
Significance of Surgery to Correct Anatomical Alterations in Pincer Nails
}

\author{
Soo Hyeon Noh, Ga Hye Na, Eun Jung Kim, Kun Park \\ Department of Dermatology, Wonkwang University School of Medicine, Iksan, Korea
}

Background: Pincer nail deformity and its causes can pose a therapeutic challenge. Ill-fitting shoes and subungual exostosis of the toes may be attributed to pincer nail formation. However, in some cases, the causes of pincer nail deformity could not be determined. The role of mechanobiology in nail configuration and deformities has rarely been considered. Objective: The present study investigated the effectiveness of surgical procedures to correct pincer nail deformity, in terms of anatomical changes measured by radiographs. Methods: Two surgical procedures, nail bed widening with matrixectomy or a dermal graft, were used on 30 nails in 20 patients with pincer deformity. Changes in the width, height, and curvature indices were assessed. Radiographs were obtained to evaluate the presence of osteophytes and measure the interphalangeal angle in terms of mechanobiology in nail configuration. Results: Preoperative and postoperative assessment results revealed marked improvement objectively and subjectively. The mean width index was greater after surgery than that before surgery $(84.4 \%$ vs. $64.8 \%)$. Both mean height and curvature indices were smaller after surgery than before preoperative $(23.0 \%$ vs. $76.7 \%$ and $1.3 \%$ vs. $2.2 \%$, respectively). Conclusion: Nail bed widening with matrixectomy, which corrects anatomical alterations in pincer nails, is suggested to be suitable for patients with pincer nail

Received November 28, 2017, Revised August 8, 2018, Accepted for publication September 19, 2018

Corresponding author: Kun Park, Department of Dermatology, Wonkwang University Hospital, Wonkwang University School of Medicine, 895 Muwang-ro, Iksan 54538, Korea. Tel: 82-63-859-1590, Fax: 82-63-842-1895, E-mail:derma@chol.com

ORCID: https://orcid.org/0000-0001-9773-6118

This is an Open Access article distributed under the terms of the Creative Commons Attribution Non-Commercial License (http://creativecommons. org/licenses/by-nc/4.0) which permits unrestricted non-commercial use, distribution, and reproduction in any medium, provided the original work is properly cited.

Copyright $₫$ The Korean Dermatological Association and The Korean Society for Investigative Dermatology deformity. (Ann Dermatol 31(1) 59 65, 2019)

-Keywords-

Nail bed widening, Pincer nail

\section{INTRODUCTION}

A pincer nail presents morphological alterations, such as a narrowed width and increased height of a nail ${ }^{1}$. It is not only aesthetically unpleasing, but also causes the nail plate to pressurize the surrounding soft tissues, resulting in ischemia with severe pain ${ }^{2}$. Foot alterations because of narrow shoes or osteoarthritis are reported to cause pincer nails ${ }^{3}$. However, the exact mechanism underlying pincer nails remains unclear. Mechanical forces influence the nail configuration and development of pincer nail deformity. In addition, the role of mechanobiology in the alteration of nails is not clearly identified.

Therefore, in this study, we determined the anatomical alterations of pincer nails and their surrounding structures through radiography. The data were used to perform surgery, and the results were analyzed.

\section{MATERIALS AND METHODS}

\section{Patients}

In this retrospective analysis, data were obtained from the medical records and clinical photographs of 44 nails from 29 patients with pincer nails, who visited the Wonkwang University Hospital Department of Dermatology between March 2010 and February 2016. We received the patient's consent form about publishing all photographic materials. To determine the nail configuration differences between pincer and normal nails, we enrolled an age- and sex- matched control group that included 40 nails from 29 
adults who did not have a significant history of nail injury. Patients with nail mycotic infections were excluded from the study. The study was approved by the Institutional Review Board of the Wonkwang University Hospital (IRB no. WKUH 201612-HRE-143).

\section{Study methods}

\section{1) Nail plate assessment}

The width, height, and curvature indices were used to determine the degree of nail plate alteration ${ }^{4,5}$. The width index (in percentage) was obtained by dividing the width of the nail tip by that of the nail root. The height index (in percentage) was obtained by dividing the height of the nail tip by the width of the nail tip. The curvature index was calculated by dividing the length of the nail tip by the width of the nail tip (Fig. 1).

\section{2) Radiographic imaging assessment}

Radiographic images were obtained to identify musculoskeletal alterations that might affect the incidence of pincer nails. A lateral image was obtained to determine osteophyte presence, and the nail length was measured (Fig. 2A). An anteroposterior image was obtained to assess the degree of the deviation, as well as the interphalangeal angle between the distal and proximal axes of the phalanx. Additionally, the base width of the distal phalanx, where the nail matrix attaches, was measured (Fig. 2B).

\section{Surgical methods and effects}

In this study, two surgical methods were used to investigate the treatment effect. Nail bed widening with matrixectomy or a dermal graft were used on 28 pincer toenails
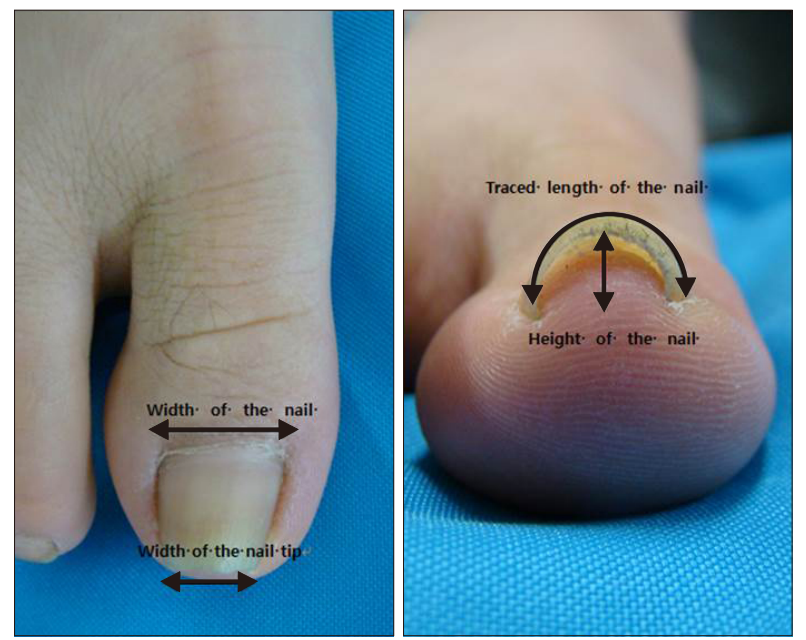

Fig. 1. Morphological assessment of width index, height index and curvature index were measured. of the 18 patients and 2 pincer thumb nails of the 2 patients. The first method was nail bed widening with matrixectomy. The nail plate was removed using mosquito with rolling and incision line was designed. The nail bed flap was raised subperiosteally around the distal interphalangeal joint. In this method, the nail matrix was detached from the bone, and when accompanied, the osteophyte was removed. Subsequently, the partial nail matrix was excised, and the contracted and distorted nail bed was widened so it could be appropriately placed and sutured (Fig. 3). The second method was the use of a dermal graft $^{6}$. The nail plate was removed from the nail bed. Incision was made distal to the hyponychium, and a tunnel was created between the nail bed and the underlying phalanx by a periosteal elevator. The dermal graft was harvested from the shin. The epidermis and subcutaneous fat were removed by scissors. The graft taken from the donor area was put into the tunnel to expand the nail bed. Postoperative complications were measured using medical record review. From surgery to suture removal (2 weeks), the medicines used for pain and infection control were evaluated. The effects of surgery on the pincer nails were followed up for at least 6 months and were analyzed using photographs.

\section{Statistical analysis}

With respect to the clinical manifestation of a pincer nail, a frequency analysis was performed, and the Pearson's correlation coefficient was calculated to determine the re-
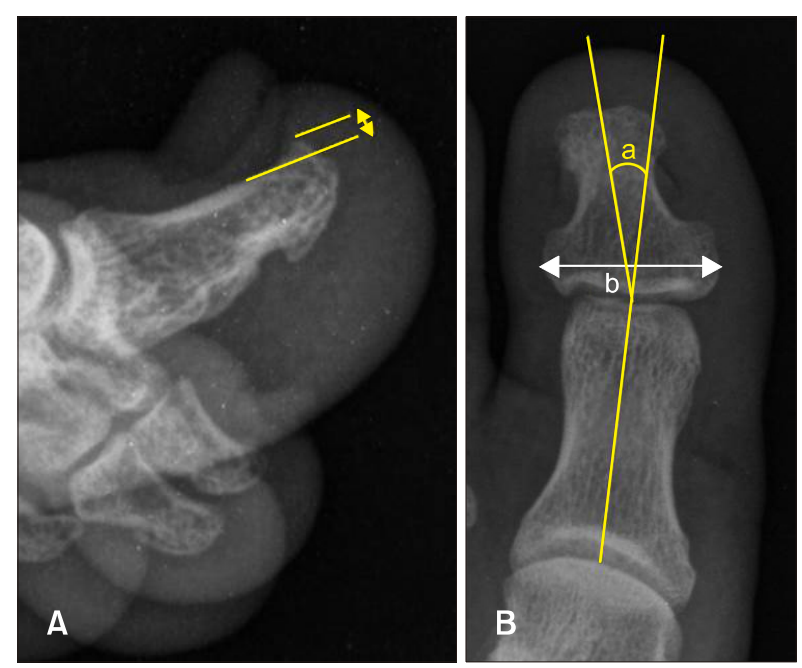

Fig. 2. (A) The lateral radiograph of the great toe showed the height of osteophyte. Arrow: height of osteophyte. (B) The anteroposterior view of the great toe showed interphalangeal angle between proximal and distal phalanges and base width of the distal phalanx. a: interphalangeal angle between proximal and distal phalanges, $b$ : base width of the distal phalanx. 

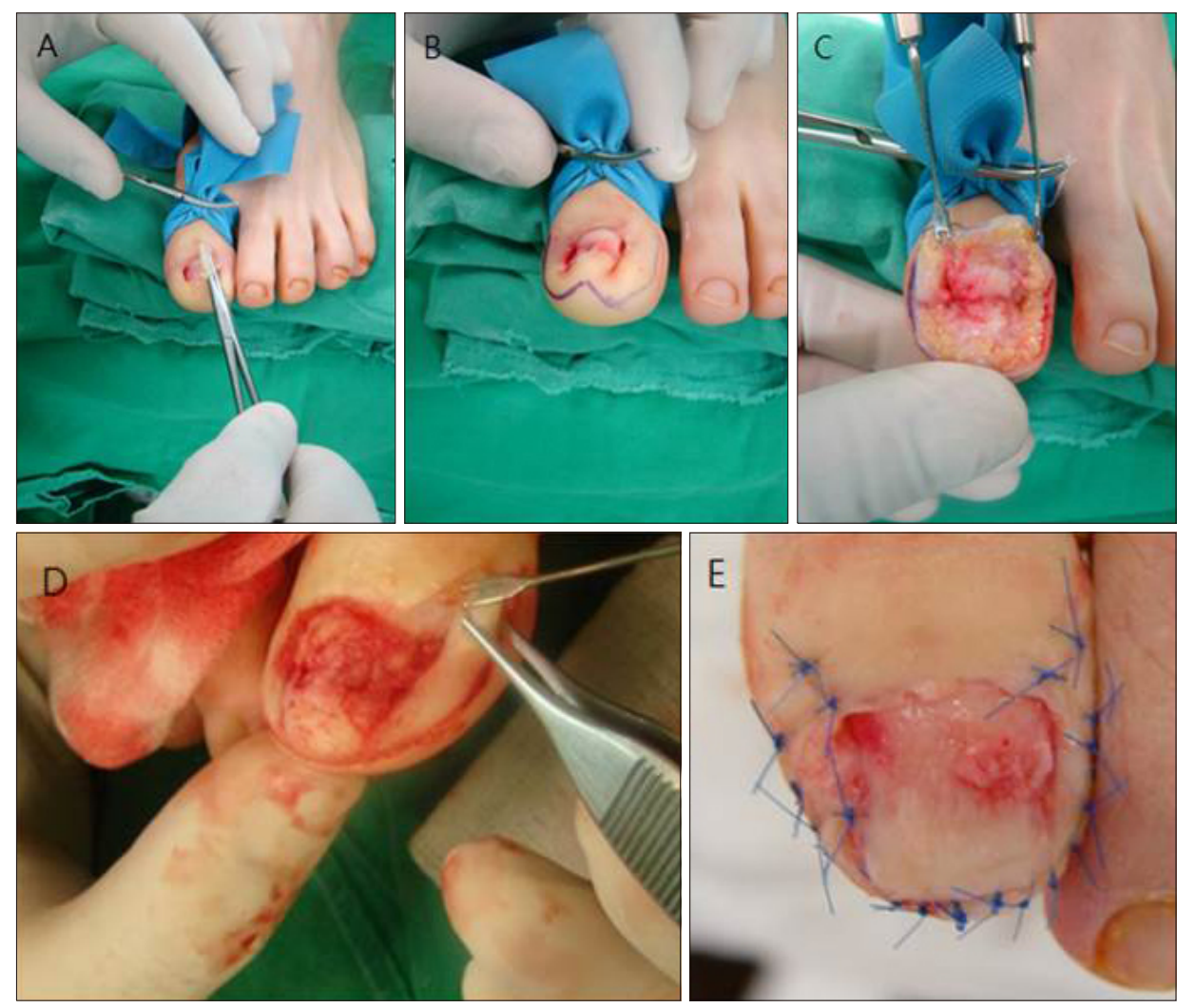

Fig. 3. Procedures of nail bed widening with matrixectomy. (A) Nail plate was removed by mosquito with rolling. (B) Incision line was designed. (C) Nail bed flap was raised subperiosteally around the distal interphalangeal joint. If the osteophyte was being, ronger was used to removing. (D) Both lateral partial nail matrixectomy was done by blade. (E) The nail bed flap was sutured into right position. lationship between the two variables. The independent sample t-test and corresponding sample t-test were used to compare the mean values. The nail plate measurements in dermal graft group were evaluated using the Wilcoxon's signed rank test. PASW statistics program (version 18.0; IBM Co., Armonk, NY, USA) was used for analytical analysis, and $p<0.05$ was considered statistically significant.

\section{RESULTS}

\section{Clinical manifestation of the patients}

Among the 29 patients, 10 and 19 were men and women, respectively. Pincer nail deformity occurred in the thumbnails and big toenails in $3(6.8 \%)$ and 41 (93.2\%) cases, respectively. Among these 41 cases, 6 (14.6\%) showed a symmetric nail shape and $35(85.4 \%)$ showed an asymmetric shape (Fig. 4, Table 1). The average symptomatic period of symmetrical and asymmetrical toenails was $17.8 \pm 12.1$ and $49.6 \pm 48.8$ months, respectively, which showed a statistically significant difference $(p=0.002$; Table 2).

\section{Nail plate assessment}

The average width, height, and curvature indices of the pincer toenails were $65.6 \% \pm 11.2 \%, 76.1 \% \pm 34.6 \%$, and $2.2 \% \pm 0.7 \%$, respectively. The patient group with pincer

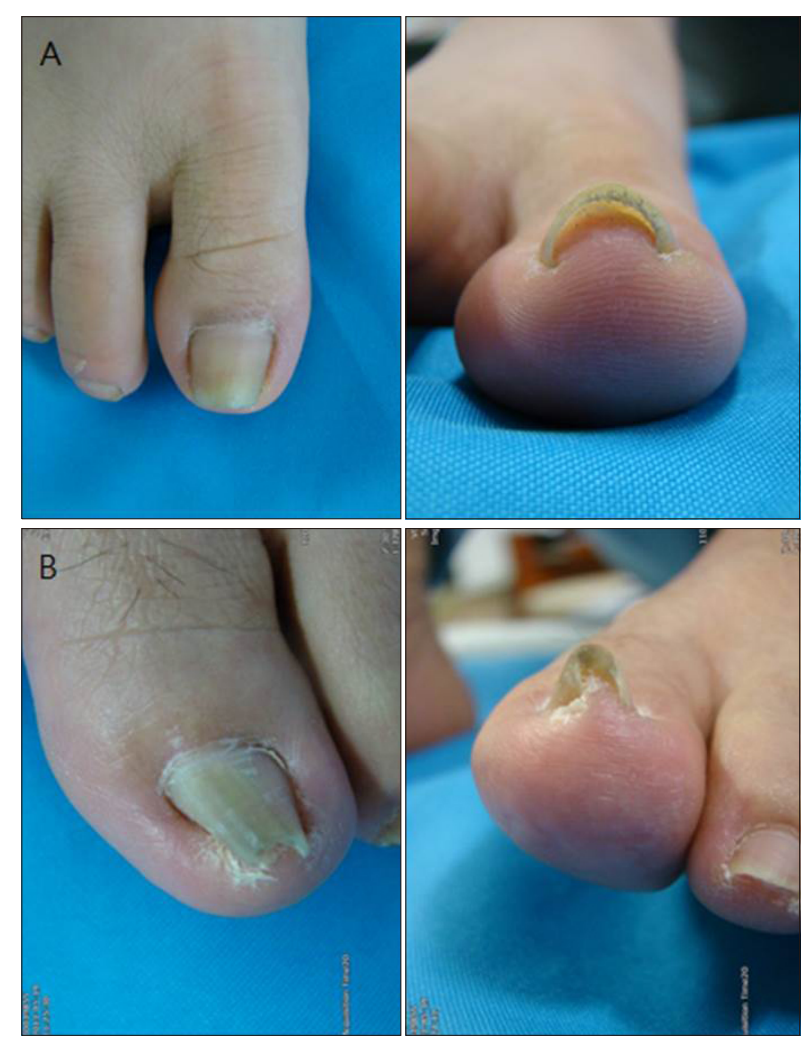

Fig. 4. Symmetric and asymmetric nail plate. (A) Symmetric nail plate. (B) Asymmetric nail plate. 
toenails showed a significantly lower width index and significantly higher height and curvature indices than did the control group. The average width, height, and curvature indices of the unaffected side of the big toenails of the patients were $84.8 \% \pm 10.9 \%, 18.6 \% \pm 8.7 \%$, and $1.2 \% \pm$ $0.2 \%$, respectively. Furthermore, the patient group with unaffected toenails yielded a significantly lower width index and higher height index than did the control group. No statistically significant difference was observed according to sex in each index (Table 3). The correlation analysis showed a negative correlation between the width and height indices, as well as between the width and curvature indices $(r=-0.552, p<0.001$ and $r=-0.428$; $p=0.004$, respectively), whereas a positive correlation was observed between the height and curvature indices $(r=0.938, p<0.001)$. All correlations were observed to be statistically significant.

Table 1. Patient characteristics

\begin{tabular}{lc}
\hline \multicolumn{1}{c}{ Characteristics } & Value \\
\hline Number of patients & 29 \\
Sex & $10(34.5)$ \\
Male & $19(65.5)$ \\
Female & \\
Location & 41 \\
Great toe & $11: 15$ \\
$\quad$ Unilateral:bilateral & $20: 21$ \\
$\quad$ Right:left & $6: 35$ \\
$\quad$ Symmetric:asymmetirc & 3 \\
Thumb & 3 \\
$\quad$ Unilateral & $42.9 \pm 21.5$ \\
Mean age (yr) & $3.5 \pm 3.8$ \\
Mean disease duration (yr) & \\
Previous treatment & $4(13.8)$ \\
Nail extraction & $4(13.8)$ \\
Clipping & $2(6.9)$ \\
Antifungal agent & $1(3.4)$ \\
Antibiotics & $18(62.1)$ \\
No treatment &
\end{tabular}

Values are presented as number (\%) or mean \pm standard deviation.

\section{Radiographic imaging assessment}

Among the 44 nails, $28(63.6 \%)$ had osteophytes in the nail bed, and all of them were observed in the pincer toenails. The average length of the osteophytes was $0.9 \pm 0.7 \mathrm{~mm}$. The average interphalangeal angle between the distal and proximal toe phalanxes of the patient group was $17.3^{\circ} \pm 6.53^{\circ}$, and the average base width of the distal toe phalanxes was $19.0 \pm 1.9 \mathrm{~mm}$. Moreover, the average interphalangeal angle of the control group was $14.0^{\circ} \pm$ $4.2^{\circ}$, and the average base width was $19.3 \pm 1.9 \mathrm{~mm}$. The interphalangeal angle of the patients was significantly greater than that of the controls $(p=0.008)$, but no significant difference was observed in the base width of the distal toe phalanxes $(p=0.437)$. In particular, the interphalangeal angle showed a positive correlation with the osteophyte height $(r=0.568 ; p<0.001)$. The average interphalangeal angle of the patients with and without osteophytes was $19.7^{\circ} \pm 5.5^{\circ}$, and $12.0^{\circ} \pm 5.6^{\circ}$, respectively $(p<0.001$; Table 4).

\section{Surgical methods and effects}

The postoperative observation period ranged from 6 to 18 months, with an average of 11.2 months. In 28 pincer toenails of 18 patients, the average width index increased from $64.8 \%$ to $84.4 \%$ after surgery. In addition, the average height index markedly decreased from $76.7 \%$ to $23.0 \%$, and the curvature index decreased from $2.2 \%$ to

Table 3. Nail plate measurement

\begin{tabular}{cllll}
\hline & Nail plates & $\begin{array}{c}\text { Width } \\
\text { index }(\%)\end{array}$ & $\begin{array}{c}\text { Height } \\
\text { index }(\%)\end{array}$ & $\begin{array}{c}\text { Curvature } \\
\text { index }\end{array}$ \\
\hline $\begin{array}{c}\text { Great } \\
\text { toe }\end{array}$ & $\begin{array}{l}\text { Control }(n=40) \\
\text { Unaffected }\end{array}$ & $96.7 \pm 8.5$ & $10.1 \pm 6.5$ & $1.1 \pm 0.1$ \\
& nail $(n=9)$ & & & \\
& Men $(n=16)$ & $65.1 \pm 8.4$ & $78.7 \pm 45.8$ & $2.3 \pm 0.9$ \\
& Female $(n=25)$ & $65.3 \pm 12.9$ & $74.4 \pm 26.0$ & $2.2 \pm 0.5$ \\
& Total $(n=41)$ & $65.6 \pm 11.2^{*}$ & $76.1 \pm 34.6^{*}$ & $2.2 \pm 0.7^{*}$ \\
Thumb & Total $(n=3)$ & $62.3 \pm 6.7$ & $51.6 \pm 10.9$ & $2.0 \pm 0.3$ \\
\hline
\end{tabular}

Values are presented as mean \pm standard deviation. *Statistically significant difference compared with the control $(p<0.05)$.

Table 2. Comparison of the parameters in patients with symmetric and asymmetric toe nails

\begin{tabular}{lcccc}
\multicolumn{1}{c}{ Toe nails } & Age $(\mathrm{yr})$ & Disease duration $(\mathrm{mo})$ & Interphalangeal angle $\left(^{\circ}\right)$ & $\begin{array}{c}\text { Distal phalangeal base } \\
\text { width }(\mathrm{mm})\end{array}$ \\
\hline Symmetric $(\mathrm{n}=6)$ & $47.7 \pm 24.8$ & $17.8 \pm 12.1$ & $14.3 \pm 4.3$ & $19.1 \pm 1.4$ \\
Asymmetric $(\mathrm{n}=35)$ & $37.0 \pm 19.5$ & $49.6 \pm 48.8$ & $17.8 \pm 6.8$ & $19.0 \pm 1.9$ \\
$p$-value & 0.241 & 0.002 & 0.237 & 0.917 \\
\hline
\end{tabular}

Values are presented as mean \pm standard deviation. 
$1.3 \%$ after surgery. All indices showed a statistically significant difference $(p<0.001$; Table 5, Fig. 5). Of 20 patients who underwent surgery, $17(85.0 \%)$ were treated with nonsteroidal anti-inflammatory drugs alone for pain control and the mean duration of use was $7.1 \pm 3.8$ days. Three patients $(15.0 \%)$ also received pethidine for a mean duration of $2 \pm 1.7$ days. Two patients developed a surgical-site infection that was confirmed by bacterial culture. The mean duration of antibiotic use was 13.5 days. Postoperative nail plate changes included thickening of the distal edge (15 nails, 50.0\%) and transverse groove (8 nails, $26.7 \%$ ).

\section{DISCUSSION}

The risk of pincer nails is high in the big toenails, but rarely occurs in the fingernails $\mathrm{s}^{7,8}$. Korean epidemiologic studies on pincer nails have reported an approximately two times higher incidence in women than in men, and the risk of pincer nails was reported to be high in the big toenails ${ }^{9}$. Similarly, the present study showed that the frequency was approximately two times higher in women than in men. All cases involved the big toenails, except for three cases that involved the fingernails. One reason may be attributed to the pressure of shoes on the toenails, as may occur in women who wear narrow or high-heeled shoes, leading to deviations of toe phalanges ${ }^{10}$.

Asymmetric toenails were present for a significantly longer duration than symmetric toenails $(49.6 \pm 48.8$ and $17.8 \pm$ 12.1 months, respectively). Pressure on the side of the nail apparatus might cause the shape to become asymmetrical over time because the matrix located on phalangeal bone is laterally deviated. The duration of pincer nails in other reports was $1 \sim 20$ years, with a median of 3.5 years $^{11}$ and mean of $7.45 \pm 8.5$ years $^{9}$. The nine patients with pincer toenails on the unaffected side had a significantly lower width index and higher height index than controls

Table 4. Comparison of the parameters in patients with osteophyte and without osteophyte

\begin{tabular}{lccc}
\hline \multicolumn{1}{c}{ Parameters } & $\begin{array}{c}\text { Osteophyte } \\
(\mathrm{n}=28)\end{array}$ & $\begin{array}{c}\text { Non- } \\
\text { osteophyte } \\
(\mathrm{n}=16)\end{array}$ & $p$-value \\
\hline Width index & $66.6 \pm 12.5$ & $63.6 \pm 7.9$ & 0.429 \\
Height index & $68.6 \pm 29.7$ & $92.3 \pm 39.9$ & 0.039 \\
Curvature index & $2.1 \pm 0.5$ & $2.5 \pm 0.9$ & 0.118 \\
Distal phalangeal base & $19.0 \pm 2.0$ & $18.9 \pm 1.7$ & 0.932 \\
$\quad$ width (mm) & & & \\
Interphalangeal angle $\left(^{\circ}\right)$ & $19.7 \pm 5.5$ & $12.0 \pm 5.6$ & $<0.001$ \\
\hline
\end{tabular}

Values are presented as mean \pm standard deviation.
( $p=0.01$ and 0.02 , respectively). This finding suggests that structural changes were present on the unaffected side, which might result in a higher risk of a pincer nail formation.

Kosaka and Kamiishi ${ }^{4}$ introduced the concept of width and height indices for the first time in 2003 to assess the severity of pincer nails. This assessment method has been widely used to determine the severity of pincer nails and treatment efficacy ${ }^{11}$. However, it can be difficult to accurately measure the width index, particularly when the nail roots are deeply buried under the skin. In addition, the width and height indices could be inaccurate when the nail is severely curved. Thus, in such cases, these indices might not ensure an accurate assessment. Hence, Yabe ${ }^{5}$ introduced the curvature index in 2013. The curvature index is the ratio obtained by dividing the length of the nail tip by the width of the nail tip; this parameter is advantageous because it can reflect severity, even when the nail is severely curved. The present study used the curvature index in addition to the width and height indices. The curvature index showed a statistically significant negative correlation with the width index, as well as a positive correlation with the height index. This study enabled more ob-

Table 5. Nail plate measurement in the pincer nail before and after treatment

\begin{tabular}{cccc}
\hline Surgical methods & $\begin{array}{c}\text { Width index } \\
(\%)\end{array}$ & $\begin{array}{c}\text { Height index } \\
(\%)\end{array}$ & $\begin{array}{c}\text { Curvature } \\
\text { index }\end{array}$ \\
\hline Great toe & & & \\
Nail bed & & & \\
widening with & & & \\
matrixectomy & & & \\
( $\mathrm{n}=25)$ & & & \\
$\quad$ Preoperative & $66.5 \pm 10.3$ & $76.9 \pm 25.0$ & $2.2 \pm 0.5$ \\
Postoperative & $86.6 \pm 8.1$ & $21.4 \pm 10.9$ & $1.2 \pm 0.2$ \\
p-value & $<0.001$ & $<0.001$ & $<0.001$ \\
Dermal graft & & & \\
method ( $\mathrm{n}=3)$ & & & \\
Preoperative & $52.1 \pm 19.7$ & $85.7 \pm 27.6$ & $2.0 \pm 0.7$ \\
Postoperative & $68.4 \pm 21.6$ & $33.4 \pm 17.1$ & $1.6 \pm 0.3$ \\
p-value & 0.285 & 0.109 & 0.593 \\
Total ( $\mathrm{n}=28)$ & & & \\
Preoperative & $64.8 \pm 11.9$ & $76.7 \pm 24.9$ & $2.2 \pm 0.5$ \\
postoperative & $84.4 \pm 11.2$ & $23.0 \pm 11.9$ & $1.3 \pm 0.2$ \\
$\quad$-value & $<0.001$ & $<0.001$ & $<0.001$ \\
Thumb & & & \\
Nail bed & & & \\
widening with & & & \\
matrixectomy & & & \\
( $\mathrm{n}=2$ ) & & & \\
Preoperative & $64.9 \pm 7.0$ & $46.7 \pm 9.4$ & $1.8 \pm 0.1$ \\
Postoperative & $82.3 \pm 3.4$ & $19.6 \pm 3.0$ & $0.9 \pm 0.3$ \\
\hline
\end{tabular}

Values are presented as mean \pm standard deviation. 

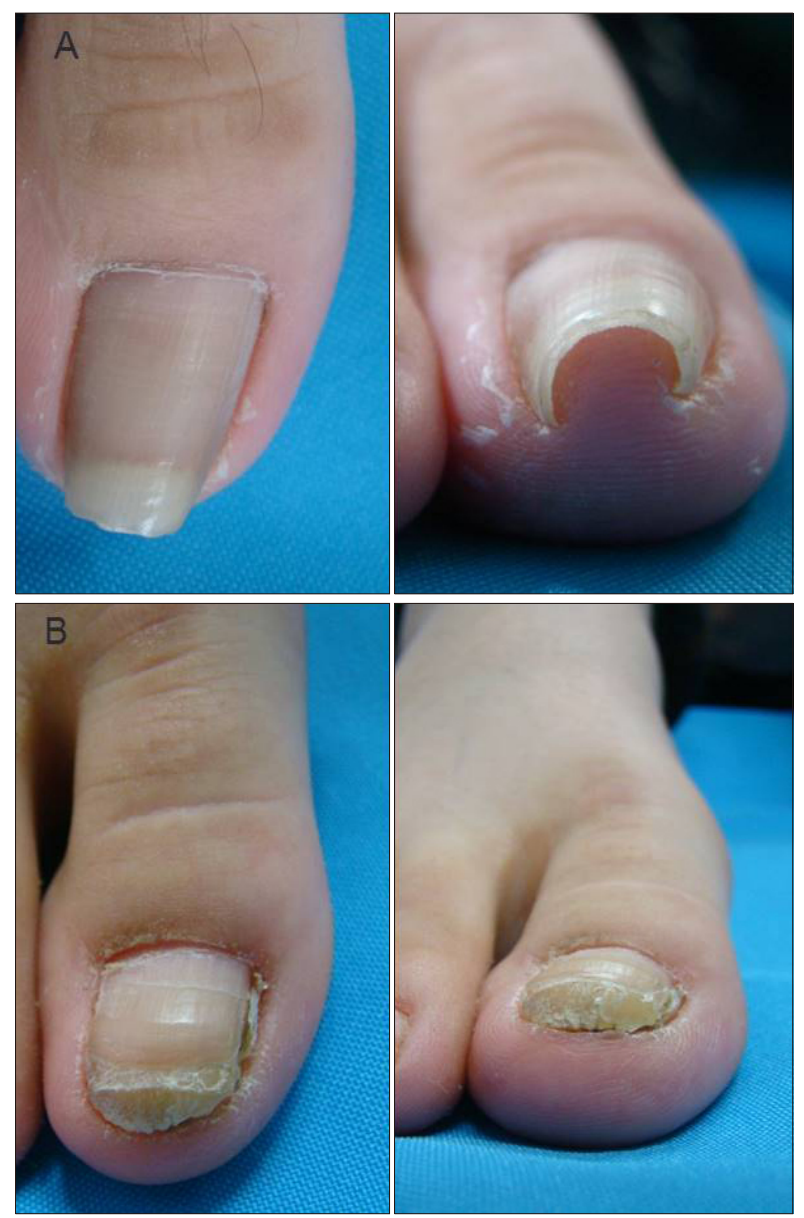

Fig. 5. (A) Presurgical toe nail. (B) Postsurgical correction by nail bed widening with matrixectomy of the pincer nail deformity (after 12 months).

jective and accurate assessment of the nails. Baran et al. ${ }^{12}$ hypothesized that the base width of the distal phalanx can increase and exert physical force on the nail matrix to form a strong fibrous connection with the distal phalanx and cause overcurvature of the nail plate, resulting in a pincer nail. However, a study comparing control and pincer nails groups reported no statistically significant differences in the base width between the two groups ${ }^{11}$. In our study, no statistically significant differences were observed between the control and patient groups in terms of the base width, and no evidence was found to support the hypothesis of Baran et al. ${ }^{12}$. Another hypothesis reported that contraction of the nail bed was followed by ventral nail plate contraction to result in a curled nail plate. It was hypothesized that curling is particularly severe distally, resulting in a pincer nail ${ }^{13,14}$. Once the pincer nail is formed, the distal phalanx exerts dorsal traction to cause a secondary osteophyte, which stimulates the subcutaneous tissue and causes contracture to worsen the pincer nail ${ }^{15}$.
A traction osteophyte is thought to be as a secondary change because osteophytes were also found in controls, with no correlation between the height of the pincer nail and the length of the osteophyte ${ }^{13}$. The present study found no correlation between the length of the osteophyte and the width, height, or curvature indices. However, the osteophyte length showed a positive correlation with the interphalangeal angle between the distal and proximal phalanx $(r=0.568 ; p<0.001)$, and the angle was found to be significantly greater in patients $\left(17.3^{\circ} \pm 6.5^{\circ}\right)$ than in controls $\left(14.0^{\circ} \pm 4.2^{\circ} ; p=0.008\right)$. Based on these findings, it was suggested that a more severe deviation of the phalanx accelerates the growth of the osteophyte, which might worsen the pincer nail.

Conservative treatment of pincer nails involves grinding the nail plate by using an abrader ${ }^{16,17}$. A 12-month follow-up revealed that this method yielded a $77 \%$ recurrence rate $^{16}$. Another conservative treatment involving the use of a shape memory alloy device showed a $52.4 \%$ recurrence rate after 10 months of follow-up ${ }^{18}$. Similarly, this conservative treatment does not yield consistent observation data, and shows a relatively high recurrence rate. Thereafter, some reports only advise palliative treatment to reduce pain ${ }^{19}$. As noted, pincer nails are characterized by structural changes. Therefore, a surgical method should be included in basic treatment. The dermal graft method cannot correct all structural changes in pincer nails; therefore, recurrence is possible ${ }^{20}$. Of 25 cases of toenail bed widening and matrixectomy, only two cases recurred $(8.0 \%)$. The recurrent pincer toenail was treated with a simple partial matrixectomy. Widening was performed by making an incision under the nail bed to cut the fibrous bands that might connect the nail bed to phalangeal bone. The nail matrix was then restored to a normal position by undermining it from the phalangeal bone. Osteophytes were observed in approximately $50 \%$ of normal, healthy nails ${ }^{13}$. Therefore, it was doubtful whether eliminating an osteophyte was necessary during the surgical procedure, and it was possible that removing it could provide another cause for further nail dystrophy. In the surgical procedure, the process of forming the flap to expand the nail bed was performed by dissecting the nail bed from the phalangeal bone. Osteophytes were naturally observed in elevated nail bed flaps; therefore, removing an osteophyte did not require additional dissection and it was easy to correct. However, the surgical procedure was more aggressive than conservative treatment, and removal of an osteophyte could result in prolonged wound healing and more pain. However, until suture removal in the second week, wound healing was good and pain was well-controlled with nonsteroidal anti-in- 
flammatory drugs. Therefore, we believe that this method of osteophyte removal is somewhat invasive, but could be effective for patients who have frequent recurrence of pincer nail deformities.

Although postoperative nail changes such as thickening of the distal edge and transverse grooving occurred, these were thought to be caused by stimulation of the nail bed during the operation and the nail matrix during matrixectomy. The nail bed contributes to nail plate production ${ }^{21}$. Therefore, these changes are expected to improve over time.

Our study was limited by being performed at a single center with a limited number of patients. In addition, the study was designed retrospectively. Therefore, a multicenter study with a larger sample size is required to confirm the results. Prospective studies should be conducted to clarify the association between outcomes of surgery to correct structural changes, such as removing an osteophyte, and adverse events. Assessment of whether the nail is improved after surgery requires a longer follow-up period.

In conclusion, considering that pincer nails induces complex anatomical alterations, a desirable treatment should be initiated to correct these alterations.

\section{ACKNOWLEDGMENT}

This work was supported by Wonkwang University in 2017.

\section{CONFLICTS OF INTEREST}

The authors have nothing to disclose.

\section{ORCID}

Soo Hyeon Noh, https://orcid.org/0000-0002-9705-9214

Ga Hye Na, https://orcid.org/0000-0003-4645-7869

Eun Jung Kim, https://orcid.org/0000-0003-3215-6811

Kun Park, https://orcid.org/0000-0001-9773-6118

\section{REFERENCES}

1. Cornelius CE 3rd, Shelley WB. Pincer nail syndrome. Arch Surg 1968;96:321-322.

2. Sorg $M$, Krüger $K$, Schattenkirchner $M$. [The pincer-nail syndrome--a rare differential diagnosis of finger end joint-/ nail involvement]. Z Rheumatol 1989;48:204-206. German.

3. Mimouni D, Ben-Amitai D. Hereditary pincer nail. Cutis
2002;69:51-53.

4. Kosaka M, Kamiishi $\mathrm{H}$. New strategy for the treatment and assessment of pincer nail. Plast Reconstr Surg 2003;111: 2014-2019.

5. Yabe T. Curvature index of pincer nail. Plast Reconstr Surg Glob Open 2013;1:e49.

6. Zook EG, Chalekson CP, Brown RE, Neumeister MW. Correction of pincer-nail deformities with autograft or homograft dermis: modified surgical technique. J Hand Surg Am 2005;30:400-403.

7. Plusjé LG. Pincer nails: a new surgical treatment. Dermatol Surg 2001;27:41-43.

8. VanDuzer ST, Taras J. Surgical correction of severe bilateral thumb pincer-nail deformity. J Hand Surg Am 2006;31: 1546-1548.

9. Lee JI, Lee YB, Oh ST, Park HJ, Cho BK. A clinical study of 35 cases of pincer nails. Ann Dermatol 2011;23:417-423.

10. Ozawa T, Yabe T, Ohashi N, Harada T, Muraoka M, Ishii M. A splint for pincer nail surgery: a convenient splinting device made of an aspiration tube. Dermatol Surg 2005;31: 94-98.

11. Jung DJ, Kim JH, Lee HY, Kim DC, Lee SI, Kim TY. Anatomical characteristics and surgical treatments of pincer nail deformity. Arch Plast Surg 2015;42:207-213.

12. Baran R, Haneke E, Richert B. Pincer nails: definition and surgical treatment. Dermatol Surg 2001;27:261-266.

13. Kosaka M, Kusuhara H, Mochizuki Y, Mori $H$, Isogai N. Morphologic study of normal, ingrown, and pincer nails. Dermatol Surg 2010;36:31-38.

14. Forslind B, Thyresson N. On the structure of the normal nail. A scanning electron microscope study. Arch Dermatol Forsch 1975;251:199-204.

15. Kosaka M, Asamura S, Wada Y, Kusada A, Nakagawa Y, Isogai N. Pincer nails treated using zigzag nail bed flap method: results of 71 toenails. Dermatol Surg 2010;36:506511.

16. Maeda N, Mizuno N, Ichikawa K. Nail abrasion: a new treatment for ingrown toe-nails. J Dermatol 1990;17:746-749.

17. Roh DK, Lee DW, Cho BK. A case of heredetary pincer nail treated with nail grinding method. Korean J Dermatol 1997; 35:971-974.

18. Kim JY, Park SY, Jin SP, Yoon HS, Cho S, Park HS. Quick and easy correction of a symptomatic pincer nail using a shape memory alloy device. Dermatol Surg 2013;39:15201526.

19. Haneke E. Pincer nails. In: Krull EA, Zook EG, Baran R, Haneke E, editors. Nail surgery: a text and atlas. Philadelphia: Lippincott Williams \& Wiklins, 2001:167-171.

20. Park SH, Kim EJ, Park K. The effectiveness of surgical correction of pincer nails using nail bed flap and bilateral partial matrixectomy, with or without osteophyte removal. Korean J Dermatol 2015;53:773-779.

21. Johnson M, Comaish JS, Shuster S. Nail is produced by the normal nail bed: a controversy resolved. $\mathrm{Br} J$ Dermatol 1991;125:27-29. 